\title{
An assessment of the performance of ISRO's SCATSAT-1 Scatterometer
}

\author{
Suchandra A. Bhowmick ${ }^{1}$, James Cotton ${ }^{2}$, Alexander Fore ${ }^{3}$, Raj Kumar ${ }^{1, *}$, \\ Christophe Payan ${ }^{4}$, Ernesto Rodríguez ${ }^{3}$, Anuja Sharma ${ }^{1}$, Bryan Stiles ${ }^{3}$, \\ Ad Stoffelen ${ }^{5}$ and Anton Verhoef ${ }^{5}$
}

${ }^{1}$ Space Applications Centre, Indian Space Research Organisation, Ahmedabad 380 015, India

${ }^{2}$ Met Office, UK

${ }^{3}$ Jet Propulsion Laboratory, California Institute of Technology, USA

${ }^{4}$ CNRM, Université de Toulouse, Météo-France, CNRS, Toulouse, France

${ }^{5}$ Royal Netherlands Meteorological Institute (KNMI), The Netherlands

SCATSAT-1 is a continuity mission for the Oceansat-2 scatterometer, OSCAT-1, which provided useful ocean vector wind observations used in, among others, oceanography, numerical weather prediction (NWP) and nowcasting. The purpose of this paper is to review the findings of the SCATSAT-1 CalVal team regarding the stability and performance of version 1.1.3 of the SCATSAT-1 data. The international CalVal team organized by ISRO included participants from various institutions in India, ISRO's Space Applications Centre, KNMI from the Netherlands, and from the USA, NOAA, and NASA's JPL. To perform the evaluation, different centres processed the data independently using heritage processors and made comparisons against NASA's Ku-band QuikSCAT mission, in situ data, and NWP models. We also provide a preliminary assessment of the impact of the SCATSAT-1 data on operational forecasts in India and Europe. We conclude that the SCATSAT-1 data shows significantly improved performance relative to ISRO's OSCAT-1 on Oceansat-2, and that the instrument seems to be stable, given the limited period of observation. The CalVal team has also identified features in the data that could benefit from calibration and processing changes, potentially leading to further improvements on data quality.

Keywords: Calibration, OSCAT-1, QuikSCAT, weather prediction.

\section{Introduction}

SCATSAT-1 is a continuity mission for the Oceansat-2 scatterometer, OSCAT-1, which provided useful ocean vector wind observations used in, among others, oceanography, numerical weather prediction (NWP) and now casting. SCATSAT- 1 carries the Ku-band OSCAT-2 scatterometer which is similar to the one flown on-board

\footnotetext{
*For correspondence. (e-mail: rksharma@sac.isro.gov.in)
}

Oceansat-2, with some enhanced features based on lessons learnt. The spacecraft is in a sun-synchronous orbit of $720 \mathrm{~km}$ altitude with an inclination of $98.1^{\circ}$. SCATSAT-1 was launched on 26 September 2016 and continues to operate nominally to this day. When launched, the satellite had an ascending equator crossing very close to that of Metop-A and Metop-B and as such it allowed cross-calibration with ASCAT. Subsequently the crossing time has been shifted by 35 minutes, which still allows frequent overlaps with ASCAT and provides more complimentary coverage.

As part of its effort to improve and assess the performance of the SCATSAT-1 mission, ISRO's Space Applications Centre (SAC) organized an international team of users from Indian space and operational weather centres, academia and Indian application users, the Koninklijk Nederlands Meteorologisch Instituut (KNMI), the US National Oceanic and Atmospheric Administration (NOAA), and NASA Jet Propulsion Laboratory (JPL). These experts met and interacted over a period of over six months, and their recommendations helped to improve in the SCATSAT-1, data products from the initial postlaunch data to the current version 1.1.3, which is publicly available and being used operationally by a number of agencies.

In this paper, we summarize the major findings from the CalVal team effort and discuss potential future improvements to the data product. All teams started with normalized radar cross section, $\sigma_{0}$, data produced by ISRO. In the next section we review mission and instrument characteristics, and the processing and operational calibration used to derive this product. A critical aspect for continuing the Ku-band $\sigma_{0}$ and wind climate data record is to achieve consistency with the QuikSCAT $\mathrm{Ku}$-band mission, which has operated continuously and stably since 1999. Given the importance of this continuity, NASA kept the QuikSCAT mission going with the express purpose of providing cross-calibration with SCATSAT-1. Subsequently we review the results of this comparison, using both ocean and land targets and assess 
the biases and stability of OSCAT-2. In this section, we also report on potential non-linearities in the system that may impact cross-calibration with a simple $\sigma_{0}$ offset. We then review the different methods used to obtain wind estimates by KNMI and JPL, as well as the calibration corrections they make to their wind products. The resulting wind products are then evaluated against in situ data, and numerical weather prediction (NWP) models. The performance and stability of SCATSAT-1 is good enough that its impact has been evaluated by various operational agencies in India and Europe that report on their initial assessment in the last section. Finally, we summarize our conclusions and make recommendations for potential future improvements to the data processing.

\section{Review SCATSAT-1 system, calibration and processing to L1B data}

\section{SCATSAT-1 mission and instrument description}

SCATSAT-1 is India's second wind scatterometer mission following the legacy of the OSCAT-1 scatterometer on Oceansat-2, which launched on 8 September 2009. Like OSCAT-1, SCATSAT-1 carries a dual polarized pencil beam scatterometer dedicated for measuring wind over the ocean. It was launched by Indian Space Research Organisation (ISRO) using PSLV C-35 on 26 September 2016 from Sriharikota and continues to operate nominally until now. Like OSCAT-1, the SCATSAT-1 payload is an active microwave scatterometer operating at a nominal frequency of $13.5 \mathrm{GHz}$ ( $\mathrm{Ku}$ band) measuring the normalized radar backscatter cross-section $\left(\sigma_{0}\right)$ from ocean surface which is used to compute wind vectors over the global ocean. With this primary objective, SCATSAT-1 is instrumental in supporting dozens of activities including weather forecasting, cyclone prediction and ocean state prediction catering to the operational weather forecasting and climate sector, naval operations, ship routing, offshore renewable energy industries around the world.

The SCATSAT-1 scatterometer, OSCAT-2, monitors $90 \%$ of global ocean with a 2 day repeat sun-synchronous orbit whose local time of descending equator crossing is $8: 45$ a.m. ( $8: 45$ p.m. ascending). Originally SCATSAT had an descending equator crossing time of $9: 20$ a.m. To increase the usefulness of the data, it was desirable to maximize the time lag with ASCAT, which had the same orbit, within the constraints of the satellite power system, and the orbit was drifted and arrested at $8: 45$ a.m. A summary of the instrument parameters is given in Table 1. OSCAT-2 has a $1 \mathrm{~m}$ diameter parabolic dish antenna with dual feed assembly to generate two pencil beams with horizontal and vertical polarization similar to OSCAT-1. The pencil beam scans at a rate of 20.5 revolutions per minute (rpm). The radar footprint provides a ground resolution cell of size $25 \times 25 \mathrm{~km}$, but finer resolution is achieved in the elevation direction via the sys- tem's intrinsic range resolution. The antenna is mounted at an angle of about $46^{\circ}$ with respect to earth nadir axis. By using two offset feeds at the focal plane of the antenna, two beams are generated; the inner beam has a boresight ground incidence angle of $48.9^{\circ}$, while the outer beam has a boresight ground incidence angle of $57.6^{\circ}$.

\section{Improvements to the OSCAT-1 design}

The OSCAT-2 design has been refined relative to its predecessor, OSCAT-1. While functionally similar to OSCAT-1, it has significantly improved payload hardware, number of modes of data acquisitions, resolution, data processing and products quality. Based on the OSCAT-1 experience, the hardware has been improved to provide flexibility and better performance. The payload has two modes: normal and enhanced. The normal mode is designed to work similar to OSCAT-1. The enhanced mode provides the following additional features: Higher precision of sample and noise data; and, post de-ramping FFT with or without windowing. To build robustness, the following additional programmable features were included: processing and noise bandwidths; start binning position for signal-plus-noise $(\mathrm{S}+\mathrm{N})$ samples and noiseonly samples; number of bins per slice for $\mathrm{S}+\mathrm{N}$ samples; overlapped binning for $\mathrm{S}+\mathrm{N}$ samples; information about I/Q reversal of reference chirp; change in frame format to accommodate new variables for programmable features; and, higher volume of data resulting from larger processing bandwidth or finer range resolution of slices.

\section{ISRO processing to $\sigma_{0} L 1 B$ data}

SCATSAT-1 data is acquired at four ground stations. There is switching over between different ground stations during $14 / 15$ orbits of data acquisition, i.e. from SVALBARD to Antarctica and vice versa. Unlike OSCAT1 , products for entire orbit are not disseminated together because sometimes entire orbit data is not available during switching over from one station to another. Instead, data products are defined every half orbit, which

Table 1. SCATSAT-1 nominal parameters

\begin{tabular}{llc}
\hline Parameter & Inner beam & Outer beam \\
\hline Orbital altitude & $720 \mathrm{~km}$ \\
Instrument frequency & $13.515 \mathrm{GHz}(\mathrm{Ku}-$ band) \\
Wind speed range & $3-30 \mathrm{~m} / \mathrm{s}$, accuracy of \\
& $1.8 \mathrm{~m} / \mathrm{s}(\mathrm{rms})$ or $10 \%$ \\
Wind direction & $0^{\circ}$ to $360^{\circ}$, accuracy of $20^{\circ} \mathrm{rms}$ \\
Wind vector cell size (resolution) & $25 \mathrm{~km} \times 25 \mathrm{~km}$ grid \\
Polarization & $H H \quad V V$ \\
Swath width & $1400 \mathrm{~km}$ & $1840 \mathrm{~km}$ \\
Scanning circle radius & $700 \mathrm{~km}$ & $920 \mathrm{~km}$ \\
Scanning rate & $20.5 \mathrm{rpm}$ & \\
\hline
\end{tabular}


provides a simpler solution to speed up the data dissemination process. The two products are designated as $\mathrm{S}-\mathrm{N}$ and N-S to represent South Pole to North Pole and North Pole to South Pole during ascending and descending phases of the orbit. The products are generated over two grid sizes of $25 \mathrm{~km}$ and $50 \mathrm{~km}$ respectively. Sensor and orbit along-track (OAT) data are used to generate normalized radar backscatter cross section, $\sigma_{0}$, at fine range resolution 'slice' level, and subsequently composited to form the 'footprint' level $\sigma_{0}$ product. Sensor and OAT data sets are first synchronized in time using derived time information. For each footprint, satellite position, velocity, attitude and other information is obtained from OAT data and the footprint is located on the Earth's surface. Received power and noise data, available in the sensor data for all the slices in a footprint, are used to compute $\sigma_{0}$, signal-to-noise ratio (SNR) and $K_{p}$. These slices are then flagged for land-sea information. Using slice information; $\sigma_{0}$, SNR and $K_{p}$ values at footprint level is also generated by compositing. Similarly, footprints are also flagged for land-sea information based on slice flagging. The final scan mode output (L1B data product) is generated in HDF-5 format. The L2A data products are gridded products with geolocation information attached to each grid cell. These products are generated using slice level $\sigma_{0}$ products by combining slices falling in the same grid cell. The processor co-locates various fore and aft observations in swath grid cells and outputs $\sigma_{0}$ by swath grid cell. For each orbit, sub satellite points at fixed grid interval $(50 \mathrm{~km}$ or $25 \mathrm{~km})$ can be obtained using satellite ephemeris information. Using outer beam swath information, the extreme points of swath corresponding to these sub satellite points are obtained. The intermediate points of swath grid are obtained using viewing geometry and earth ellipsoid information. Thus, a swath grid for each orbit is formed. Each $\sigma_{0}$ observation is classified (as outer fore, outer aft, inner fore or inner aft) and assigned to a grid cell based on its latitude and longitude information. L2A data products for each half-revolution are generated in HDF-5 format for both $50 \mathrm{~km} \times 50 \mathrm{~km}$ and $25 \mathrm{~km} \times$ $25 \mathrm{~km}$ grid spacing.

\section{ISRO operational quality assessment and calibration of $\sigma_{0}$}

The precision of the SCATSAT- 1 winds and land $\sigma_{0}$ measurements depends on good operational calibration of the $\sigma_{0}$ data to account for instrument variations. At ISRO, a two-step calibration process is implemented. The first step is an in-flight data quality evaluation (DQE), which is followed by calibration (CAL) of measured $\sigma_{0}$. Finally, a validation (VAL) of final wind product derived from $\sigma_{0}$ using a geophysical model function is performed. DQE monitors the instrument health along with sensor performance in near real time basis. CAL on the other hand guarantees stability and precision of measurements. This is done by quantifying the measurement errors and biases of the instrument. VAL justifies quality of wind in comparison to other observations and guarantees suitability of wind for various applications.

SCATSAT-1, raw data (level-0) from each acquisition passes through DQE chain for conformance of data quality. In case of any deviations in sensor data, it is reported immediately by the data product team. Moreover, DQE system is capable of generating time series for selected parameters to observe the parameter behaviour over a period of time. Monitoring using the DQE processors has shown a stable signature of the power at front end switch assembly (FESA) from the first day of SCATSAT-1 operations. Figure 1 shows the time evolution of the FESA calibration power. The loop back calibration power (Figure 2) also shows a very stable signature in case of SCATSAT for both inner and outer beams.

The CAL process is based on $\sigma_{0}$ analysis using slice level L1B $\sigma_{0}$ that gives a gross idea about presence of any attitude dependent biases in the data. To test if the slice level $\sigma_{0}$ is miss-balanced, histograms of the $\sigma_{0}$ for each slice is computed for global land and ocean. In ideal case one can expect a peak to peak match for all such histograms. Figure 3 shows typical example of slice wise histogram of $\sigma_{0}$ for entire globe for inner and outer ascending aft beams for latest data. Very clearly the slice level $\sigma_{0}$ is balanced and does not have any significant shift. In converting slice level $\sigma_{0}$ to the corresponding footprint level, a residual without any trend is expected if the system is devoid of any azimuth dependent biases. In case of SCATSAT-1, $\gamma_{0}$ which is $\sigma_{0}$ normalized with cosine of the incidence angle, is computed over homogeneous targets like Amazon. The bias of slice level $\gamma_{0}$ and footprint level $\gamma_{0}$ are computed with respect to the antenna azimuth. For both inner and outer beam no significant azimuth dependent bias has been observed in SCATSAT1 (Figure 4). The Level 2A (L2A) $\sigma_{0}$ data analysis over the Amazon area shows small biases among the fore and aft measurements of SCATSAT which implies the consistency among the near simultaneous observations (figure not shown). Over the ocean the aft and fore biases in each wind vector cell of SCATSAT is mild, emphasizing on the high quality of the SCATSAT wind. On the other hand, OSCAT-1 exhibited wind vector cell wise biases between fore and aft looks are much higher than OSCAT-2, showing the improved measurement quality and less errors in the wind product (Figure 5).

\section{Assessment of $\sigma_{0}$ stability, calibration and system linearity}

\section{ISRO assessment of $\sigma_{0}$ stability and consistency using land and ocean targets}

Tracking a possible drift of OSCAT-2 in time requires a reference that is considered to be stable and not have a 


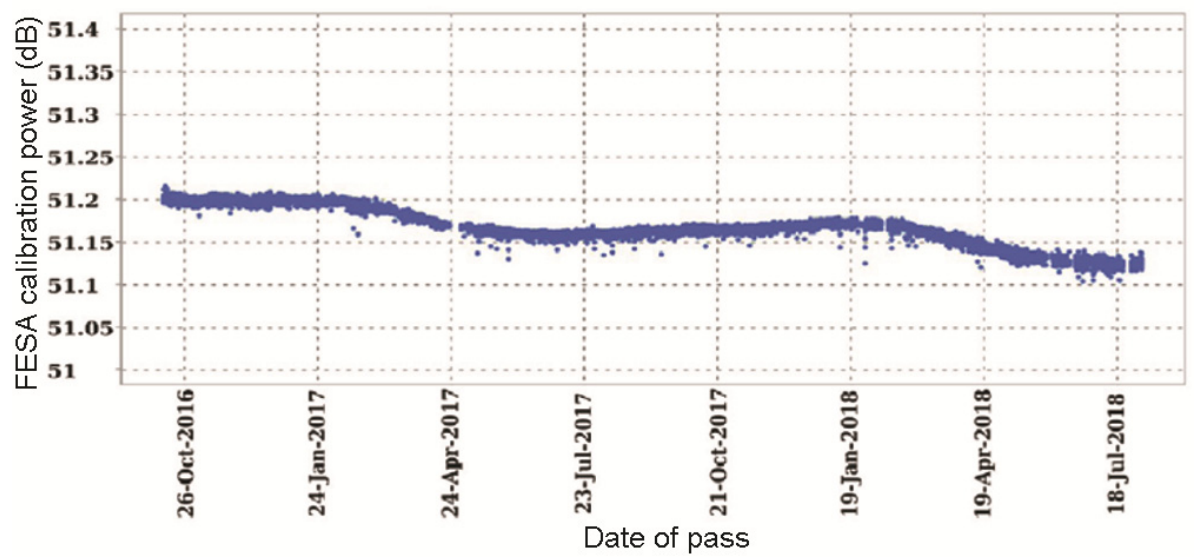

Figure 1. FESA calibration power over nearly a year of operation.

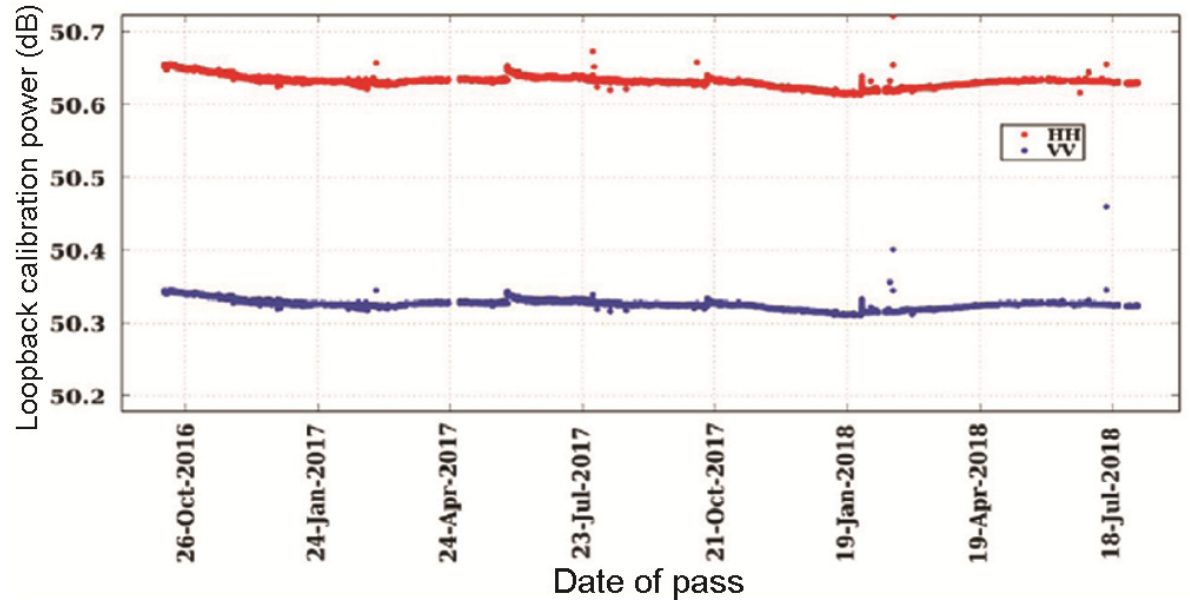

Figure 2. Loop back calibration power for inner/outer beam.
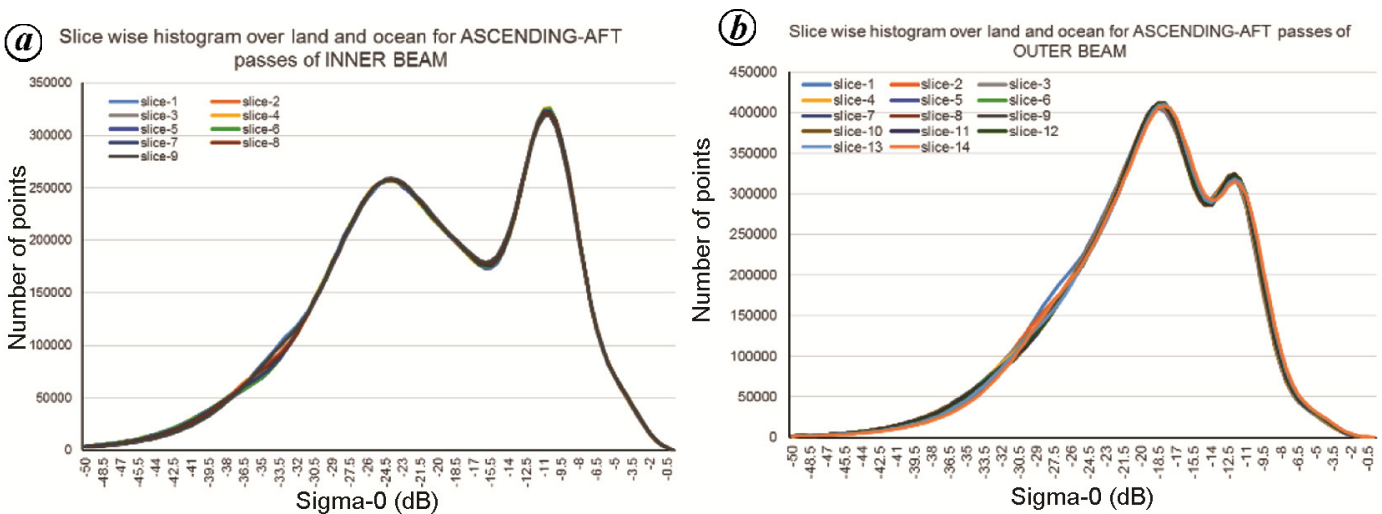

Figure 3. Histogram of $\sigma_{0}$ over global land and ocean for each slice of $(\boldsymbol{a})$ inner-ascending-aft $(\boldsymbol{b})$ outer-ascending-aft passes. Data of Julian day 90-99 of 2017 has been utilized for histogram construction.

drift. The Amazon rainforest has proven itself to be a relatively stable target $^{1-4}$; however, it does have some seasonal changes and possible permanent changes due to deforestation. To help correct for these effects we use QuikSCAT which is sampled at the same time of year, sampled over the same region, but not at the same local time of day as SCATSAT-1. We adjust the attitude of the QuikSCAT spacecraft to attain the same local incidence angles for each beam as for SCATSAT-1. We can only use one beam at a time in this mode, so every two weeks we switch operation of QuikSCAT between the modes corresponding to the inner/outer beam polarization and 
incidence angles of SCATSAT-1. We have been operating QuikSCAT in this way since late 2016 with the exception of eclipse season, which runs from midNovember through the end of January each winter.

In Figure 6 on the upper-left we plot the OSCAT-2 $\gamma_{0}$ for inner beam as circles with colours for each version and QuikSCAT inner beam as black $x$; on the upper-right we plot the same for outer beam; in the lower left we plot the difference between OSCAT-2 and QuikSCAT for inner beam, and in the lower-right we show the same for outer beam. We note that in 2017 the OSCAT- $2 \gamma_{0}$ tracks QuikSCAT quite well, capturing the seasonal peak. Comparing the 2018 data we find no significant change in OSCAT-2 as compared to QuikSCAT for the inner beam indicating no discernible drift at this point.

\section{Absolute calibration using QuikSCAT data}

To cross-calibrate OSCAT-2 to QuikSCAT we use two main methods: an ocean-based analysis and an Amazon
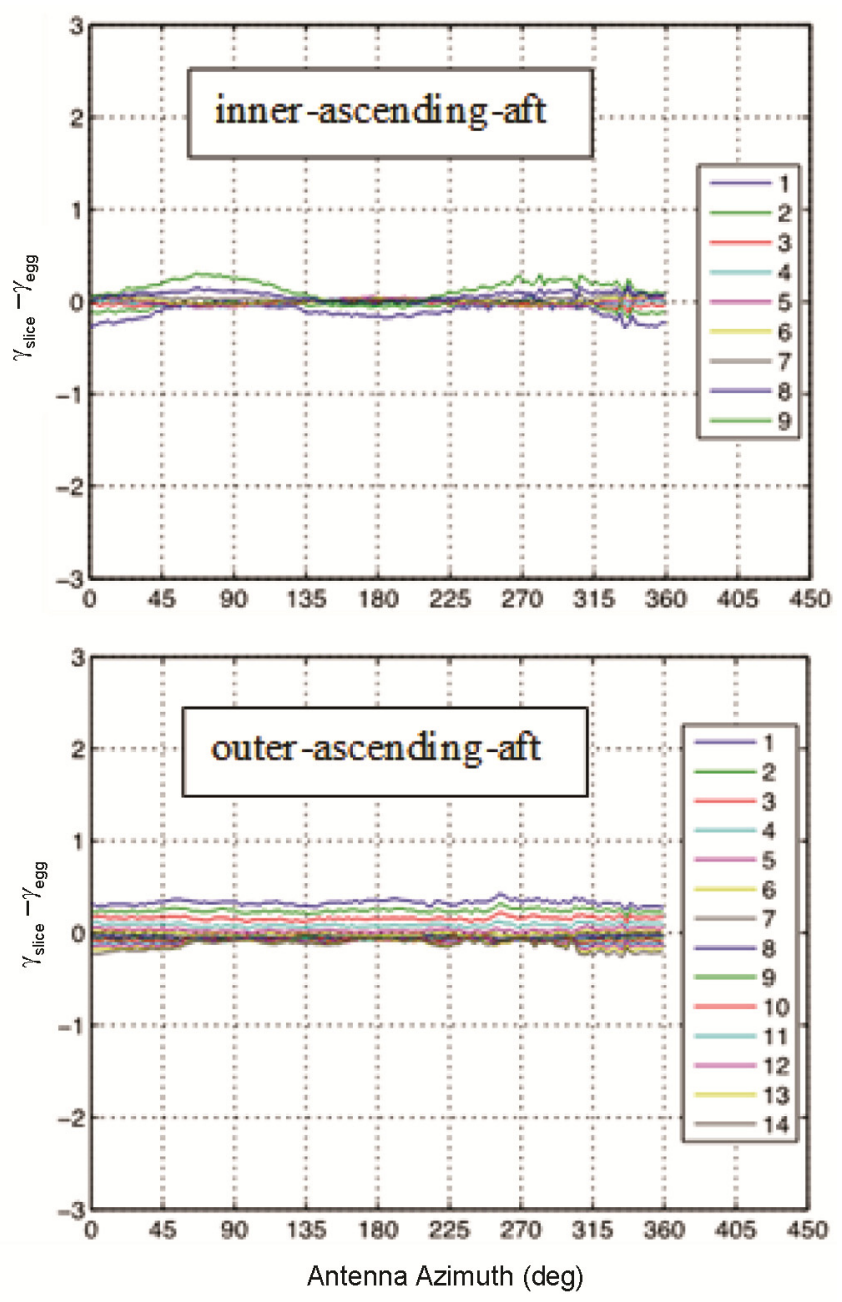

Figure 4. $\gamma_{0}$ 'egg' (i.e. footprint) and slice differences over homogeneous targets (using L1B Data of Julian day 90-99 of 2017) for the inner (upper) and (outer) beams as a function of azimuth angle and as a function of slice number (colour). rainforest-based analysis. Using the ocean as a reference surface along with an ancillary wind model, we apply the techniques developed ${ }^{5}$ for the cross-calibration of OSCAT1 to determine the calibration of OSCAT-2 relative to QuikSCAT. For the Amazon analysis, we compute the $\gamma_{0}$ for QuikSCAT and for OSCAT-2. We correct for the differing local times of day for each instrument using a climatology of Amazon $\gamma_{0}$ developed with RapidScat data. For both methods, we determine one calibration offset from each two-week period of QuikSCAT, and accumulate data as we alternate the operation of QuikSCAT between the two OSCAT- 2 modes. In Table 2 we summarize the various cross-calibration estimates obtained using the Ocean and Amazon as reference surfaces using QuikSCAT. We show these results for OSCAT-2, OSCAT1 , and RapidScat and for all three, the calibration estimates from the Ocean are not in total agreement with those from the Amazon. Note that for OSCAT-2 and OSCAT-1 JPL applies a correction in L2B processing (since ISRO produces the L1B data), but for RapidScat the L1B processor is adjusted to re-generate the data. In this case the analysis was performed on calibrated data as a validation exercise. For OSCAT-2, we use the oceanbased calibration estimate from QuikSCAT with an additional $(0.2,0.3) \mathrm{dB}$ adjustment for $H H$ and $V V$ respectively.

Note that this calibration process assumes that a single offset attenuation is sufficient to calibrate the instrument. This will be the case if the system is linear, but may not be sufficient if non-linearities are present, as discussed below.

\section{Slice calibration}

To assess the slice calibration of the range slices, we compare the slices to the footprints, over ocean, using the geophysical model function (GMF) to account for relative changes in $\sigma_{0}$ as a function of incidence angle. We compute the slice residual, which is the ratio of the slice $\sigma_{0}$ to the footprint $\sigma_{0}$ divided by the ratio of the slice model $\sigma_{0}$ to the footprint model $\sigma_{0}$. This analysis assumes that the ocean surface winds do not vary significantly over the antenna footprint. In Figure 7, we plot the slice misbalance estimates as a function of slice number and antenna azimuth angle. We find that SCATSAT-1 1.1.3 data does not have a significant slice mis-balance and does not require correction.

\section{Potential system non-linearities for $\sigma_{0}$}

Two fundamentally important aspects of any scatterometer are its stability and linearity. In the previous sections we examined the OSCAT-2 stability. In this section we address potential system non-linearities. Our premise is that, for given wavelength, polarization and geometry, $\sigma_{0}$ should be identical in identical geophysical conditions 

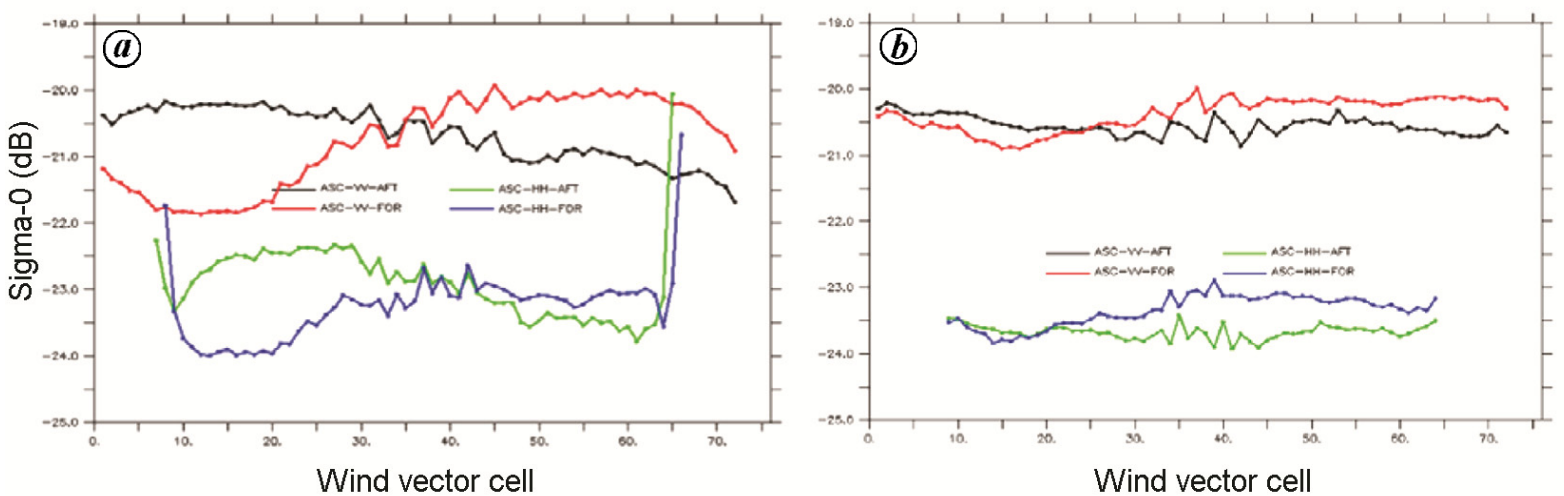

Figure 5. $\sigma_{0}$ over ocean in each wind vector cell for inner/outer, aft/fore ascending beam in (a) OSCAT-1 (data utilized $274-365$ of 2013) and (b) SCATSAT-1 (data utilized 001-099 of 2017).
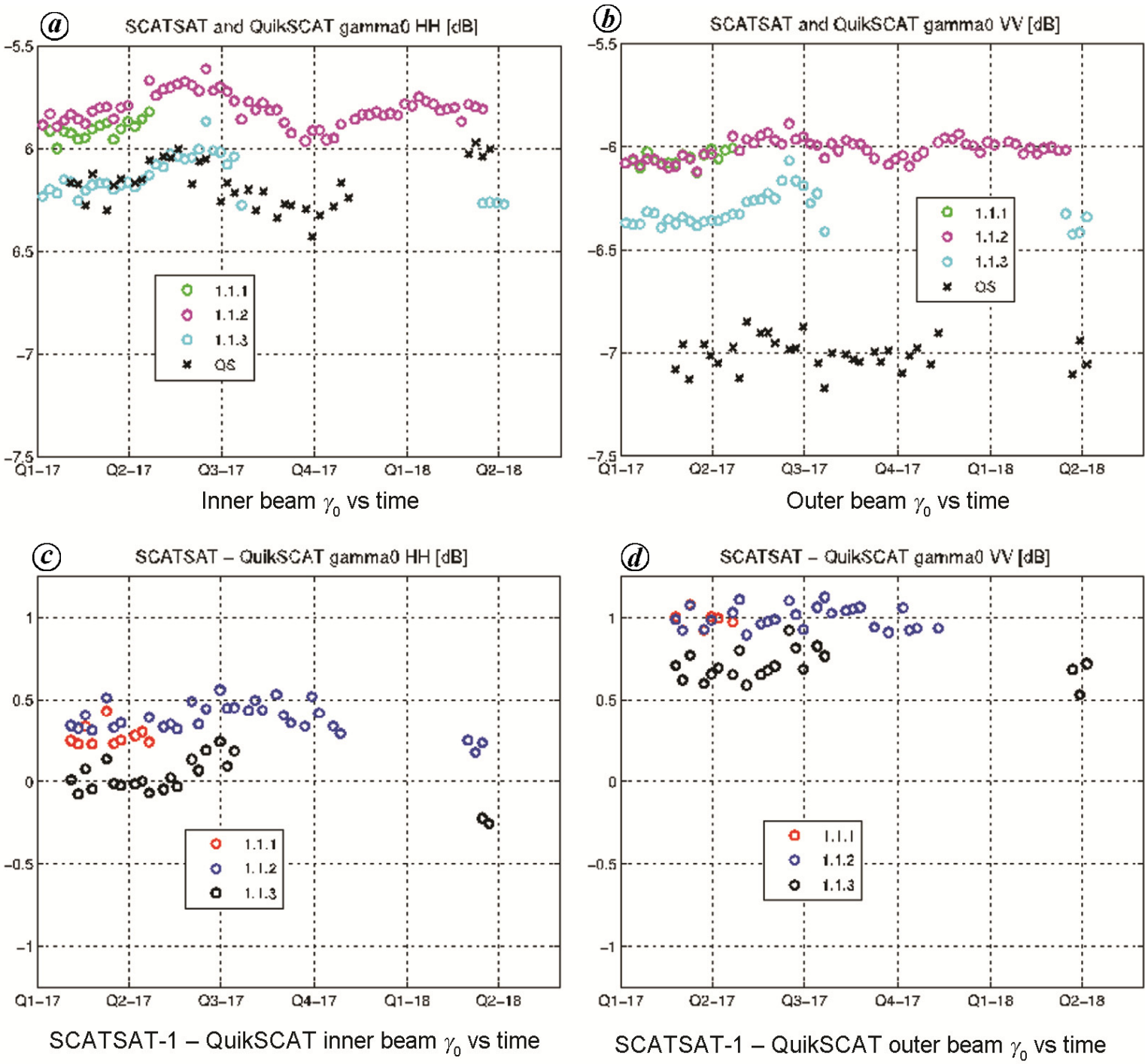

Figure 6. $\boldsymbol{a}$, Inner beam $\gamma_{0}$ versus time; $\boldsymbol{b}$, same for outer beam; $\boldsymbol{c}$, OSCAT-2 - QuikSCAT inner beam $\gamma_{0}$ versus time; $\boldsymbol{d}$, same for outer beam. We plot all versions of OSCAT-2 data as different colours, all with circle markers, and QuikSCAT with black $x$. 
Table 2. Table of calibration adjustments determined using Amazon cross-comparison to QuikSCAT, Ocean cross-comparison to QuikSCAT, the difference between the two, and the adjustments used in JPL's data products. We show this for OSCAT-2, OSCAT-1 and RapidScat. Note that the numbers here are an offset relative to how the data was processed, in the case of RapidScat the analysis was done on calibrated data as a validation of the calibration

\begin{tabular}{lcccc}
\hline & Ocean & Amazon & Difference & \\
\hline OSCAT-2 HH & +0.31 & -0.15 & +0.46 & +0.51 \\
OSCAT-2 VV & -0.56 & -0.82 & +0.26 & -0.26 \\
OSCAT-1 HH & +0.53 & +0.15 & +0.38 & +0.53 \\
OSCAT-1 VV & +0.30 & -0.06 & +0.36 & +0.30 \\
RapidSCAT HH & +0.02 & +0.02 & 0.00 & 0.00 \\
RapidSCAT VV & +0.15 & -0.06 & -0.21 & 0.00 \\
\hline
\end{tabular}

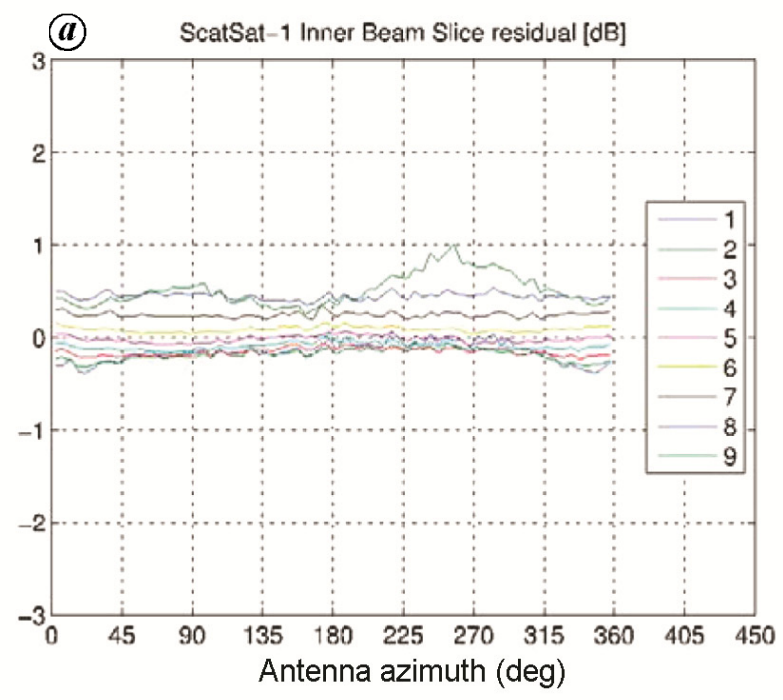

1.1.3 innter beam

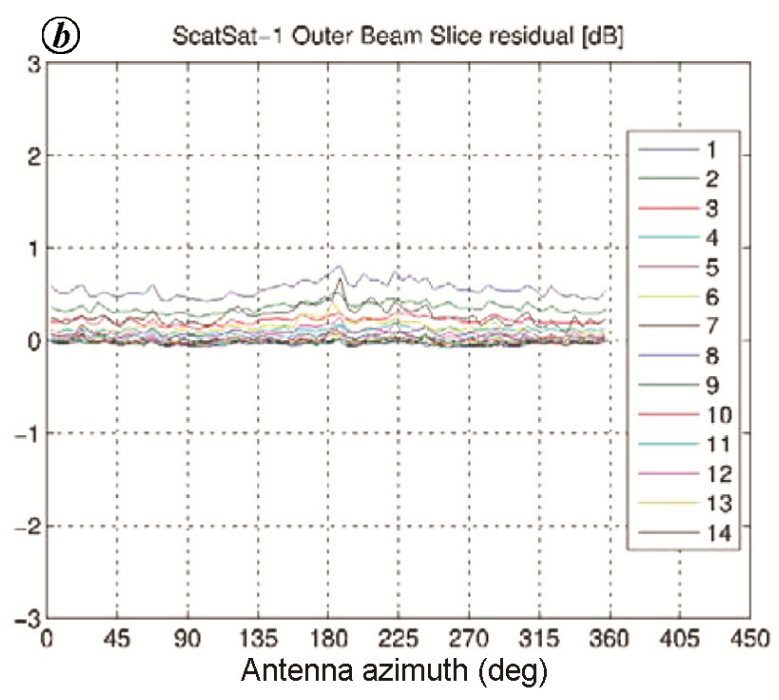

1.1.3 outer beam

Figure 7. (a) Inner beam slice mis-balance estimates based on ocean and (b) same for outer beam, both for SCATSAT-1 1.1.3 data. Version 1.1.3 does not require a significant slice balance correction to be applied.

and independent of instrument settings. The processing teams are particularly interested to remove $\sigma_{0}$-dependent instrument biases as they interfere with $\mathrm{Ku}$-band wind and SST dependencies ${ }^{6}$.

In our analysis, comparison of OSCAT-2 with QuikSCAT, RapidScat and OSCAT-1 behaviour for given GMF and Numerical Weather Prediction (NWP) input reveals potential system non-linearities. In particular, an unexpected high speed bias of OSCAT-2 with respect to ASCAT is observed, which is not seen for OSCAT-1, QuikSCAT or RapidScat. This bias can be reproduced against the European Center for Medium-range Weather Forecasts (ECMWF) model as depicted in Figure 8, which uses KNMI wind processing (see below). The effect is similar for winds derived from only $\mathrm{VV}$ or $\mathrm{HH}$, present in scatter plots of simulated and measured backscatter, where a generic non-linear $\sigma_{0}$ correction in $\mathrm{dB}$ above $-19 \mathrm{~dB}$ of $0.11\left(\sigma_{0}\right.$ in $\left.\mathrm{dB}+19\right)$ solves all $V V, H H$ and wind biases to a large extent (Figure 9).

\section{Wind processing and performance assessment}

\section{Description of Wind Estimation algorithms and GMF's}

All participants in the SCATSAT-1 CalVal team used the ISRO SCATSAT-1 level 1.1.3 L1B data as a starting point, but processing beyond L1B was performed differently by each team, building on the heritage of their operational data products. The ISRO processing is described elsewhere in this issue, while this section describes the processing used by JPL and KNMI to generate wind data products.

JPL processing description: The first step in processing $\sigma_{0}$ data to Ocean vector winds (OVW) for typical pencilbeam scatterometers is based on the choice of $\sigma_{0}$ data to use full-aperture footprints or 'slices'. Typically, JPL uses slice data, as it is higher resolution; however, for 

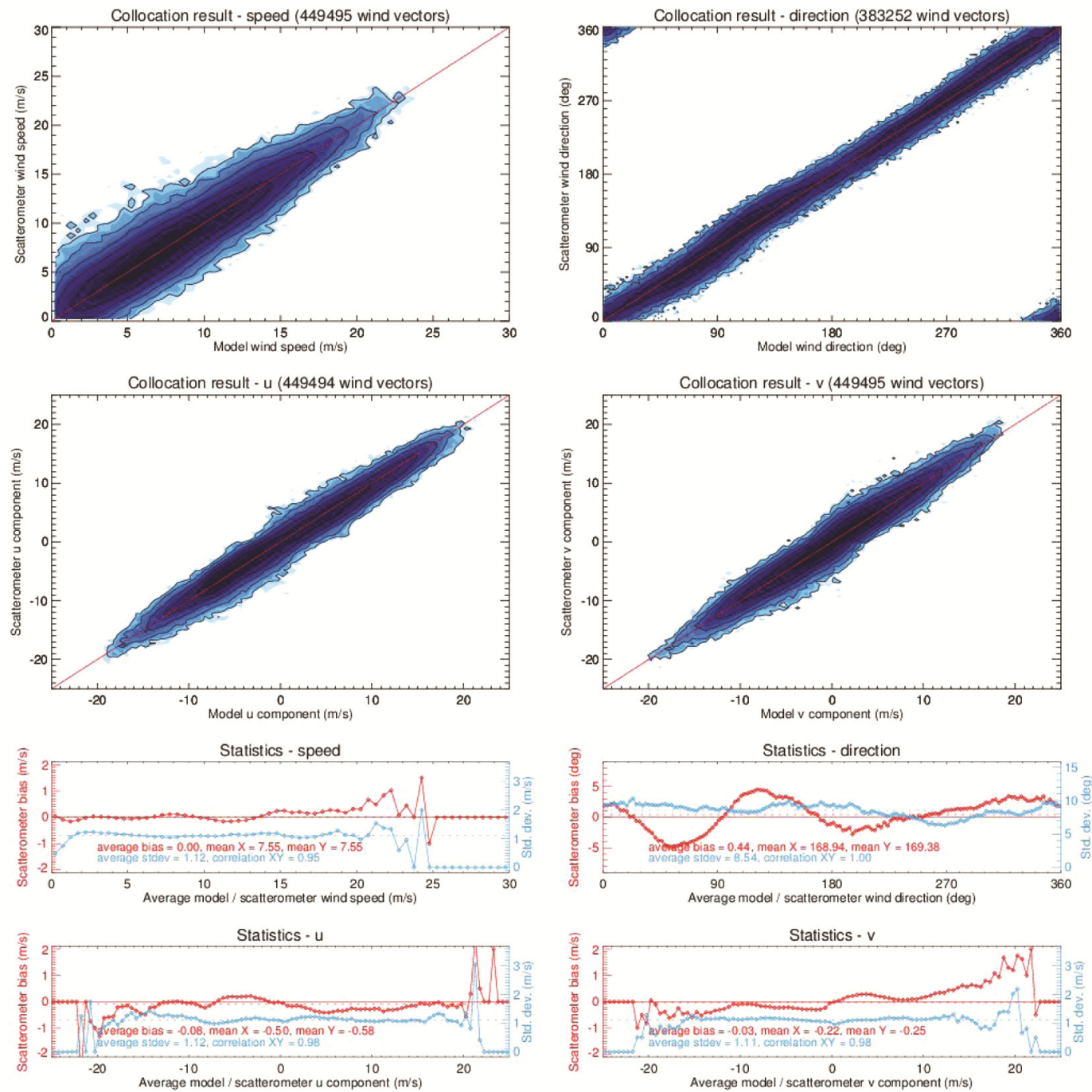

Figure 8. Two-dimensional histograms of wind speed, direction (with respect to wind coming from the North), $u$ and $v$ components of $25 \mathrm{~km}$ ScatSat-1 wind product versus the ECMWF model forecast winds from 4-5 April 2018 (top panels). The corresponding biases (red) and standard deviations (blue) as a function of the average scatterometer and model winds are shown at the bottom. The bias is set to 0 for empty bins, and standard deviation is set to 0 if bins contain less than two data points ${ }^{21}$.
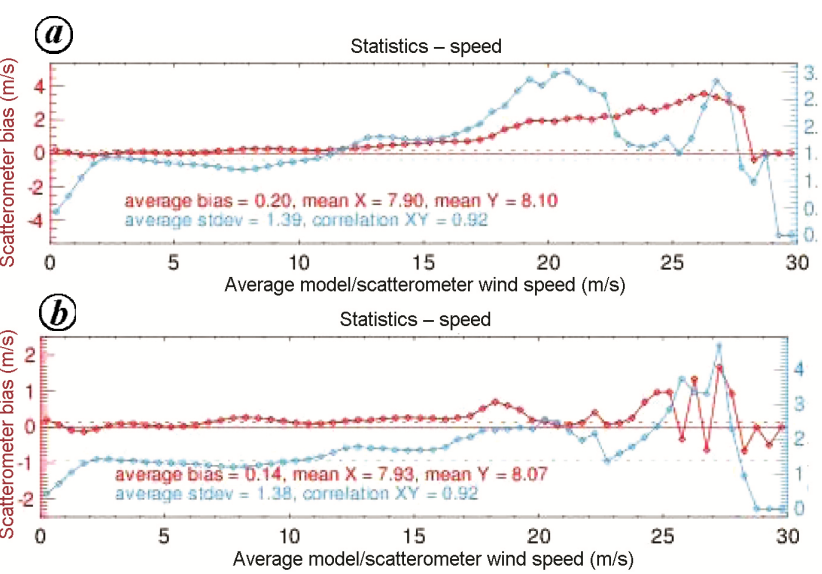

Figure 9. Wind speed bias and standard deviation of OSCAT-2 winds versus ECMWF before $(\boldsymbol{a})$ and $\operatorname{after}(\boldsymbol{b})$ non-linear $\sigma_{0}$ bias correction. climate-quality applications the footprint data may be preferable if there are residual calibration issues for the slices. Footprint data are significantly easier to calibrate as they are full aperture measurements and only sensitive to the overall gain, while slices are very sensitive to the exact shape of the antenna pattern, and residual offsets in slice locations may lead to large errors.

The next step creates the swath grid, centered on the spacecraft nadir track, and bins the $\sigma_{0}$ observations into that swath grid. The Space Oblique Mercator projection is used $^{7}$ to define the level 2A (L2A) swath grid. Various methods are used in the community to put $\sigma_{0}$ measurements into particular grid cells. JPL oversamples the $\sigma_{0}$ slice data into the L2A grid using the overlap technique ${ }^{8}$. This operation yields up to four flavours of observations per wind vector cell (WVC) with similar viewing 
geometries: ( $H H$-fore, $H H$-aft, $V V$-fore, $V V$-aft). Here 'fore' indicates that the observation is from the half of the antenna scan where the beam is looking along the velocity vector relative to the instantaneous nadir point, and 'aft' indicates it is from the other half of antenna scan. This yields a wide swath of WVCs: for OSCAT-2 it is $1800 \mathrm{~km}$ wide with varying azimuthal sampling across the swath. In the centre of the swath the fore and aft observations are typically $180^{\circ}$ apart in azimuth angle while at the edges of the swath they are nearly the same. In the regions between the far swath and nadir is the 'sweet zone' where the geometry of the various observations give the best OVW performance.

Then for each WVC we perform a maximum likelihood estimate (MLE) of the OVW that minimizes an objective function. For QuikSCAT and RapidScat, the following formulation of the objective function is used by JPL

$$
F(w, \phi)=\sum_{i} \frac{\left[\sigma_{0 i}-\sigma_{0 m i}(w, \phi)\right]^{2}}{\left[K_{p} \sigma_{0 m i}(w, \phi)\right]^{2}} .
$$

Here $i$ indicates the $i$ th measurement that is binned into that WVC, $\sigma_{0 i}$ is the observed cross-section for measurement $i, \sigma_{0 m i}$ the GMF value for measurement $i$, evaluated at wind speed $w$ and relative azimuth angle $\phi$ and $K_{p}$ is the predicted normalized error. The GMF is an empirically derived mapping from ocean surface winds and measurement geometry to expected $\sigma_{0}$ while the $K_{p}$ is determined from various radar parameters and estimated errors. For this paper, JPL used an updated version of the most recent QuikSCAT $\mathrm{GMF}^{9}$ that is extended to the OSCAT-2 incidence angles. The minimization of this objective function typically yields up to four possible solutions, called ambiguities. Finally, the JPL processor performs Directional Interval Retrieval with THresholded nudging (DIRTH) ${ }^{10}$ to select the best wind vector among those ambiguities and create the final OVW product.

KNMI processing description: KNMI is involved in the European organization for Meteorological Satellites (EUMETSAT) Ocean and Sea Ice Satellite Application Facility (OSI SAF), as the centre where wind processing is carried out for scatterometers, including OSCAT-2 $2^{11,12}$. More general information on the OSI SAF project is available on the OSI SAF website: http://www.osisaf.org/. The OSI SAF processing algorithms for the OSCAT-2 wind processing are adopted from the algorithms as developed for SeaWinds, RapidScat and OSCAT-1 on Oceansat-2 (ref. 13). When calibrated geophysical backscatter measurements are available, the wind processing of the different $\mathrm{Ku}$-band pencil-beam scatterometers is identical. The wind processing software which is used, the Pencil beam Wind Processor (PenWP), is capable of processing data from SeaWinds on QuikSCAT, OSCAT-1, RapidScat and HY-2A scatterometers and publicly available. PenWP utilizes the NSCAT-4 Geophysical Model Function (GMF) ${ }^{13}$, which is available for all prevailing incidence angles. In order to handle instrument differences well, particularly noise characteristics, some parts of the processing were re-tuned for SCATSAT-1, mainly the normalization of the maximum likelihood estimator (MLE) and the tuning of the quality control $^{14}$.

No absolute instrumental instrument calibration exists for $\mathrm{Ku}$-band pencil-beam scatterometers. $\mathrm{Ku}-$ band pencilbeam backscatter distributions should however be matched to achieve wind intercalibration of all space-borne scatterometer instruments. KNMI thus developed methods that calibrate the winds of each scatterometer effectively to the mean winds at collocated moored buoys. No significant signs of azimuth (or WVC) dependent instrument biases have been found for SCATSAT-1. Also the beam incidence angles are constant and hence we have chosen to apply backscatter corrections that are only dependent on the beam polarization. The goal of applying backscatter corrections was to minimize wind speed biases between scatterometer winds on the one hand and buoy and numerical weather prediction (NWP) winds on the other hand. Moreover, we first assume only linear calibration is needed, thus effectively evaluating a $V V$ and $H H$ backscatter bias in $\mathrm{dB}$. With this in mind, the calibration correction for $V V$ has been obtained by looking at the outer swath data (where no $H H$ data are available) and choosing a calibration amount that yields minimum wind speed biases. Subsequently, the swath part containing both $H H$ and $V V$ was considered, the $V V$ correction was applied and a $H H$ correction was obtained that again yields minimum biases. In this simple way, within a few iterations the two calibration coefficients could be obtained: (i) For $H H,+0.67 \mathrm{~dB}$ has been added in the $25 \mathrm{~km}$ products and $+0.60 \mathrm{~dB}$ in the $50 \mathrm{~km}$ products; (ii) For $V V$, $+0.02 \mathrm{~dB}$ has been added in the $25 \mathrm{~km}$ products and $-0.05 \mathrm{~dB}$ in the $50 \mathrm{~km}$ products. However, as noted previously, a further backscatter correction was needed for values above $-19 \mathrm{~dB}$ in both $V V$ and $H H$.

\section{Performance comparison against in situ data}

After calibration, KNMI uses the NWP SAF Pencil-beam Wind-data Processor (PenWP) for all available pencilbean scatterometers. Next, scatterometer winds from KNMI are compared with in situ buoy wind measurements. The buoy winds are distributed through the Global Telecommunication System (GTS) and have been retrieved from the ECMWF MARS archive. The buoy data are quality controlled and (if necessary) blacklisted by $\mathrm{ECMWF}^{15}$. We used a set of approximately 160 moored buoys spread over the oceans, most of them in 
the tropical oceans and near Europe and North America. These buoys are also used in the validations that are routinely performed for the OSI SAF wind products; see the links on http://www.knmi.nl/scatterometer/osisaf/. The buoy winds are measured hourly by averaging the wind speed and direction over $10 \mathrm{~min}$. The real winds at a given anemometer height have been converted to $10 \mathrm{~m}$ equivalent-neutral winds using the Liu, Katsaros and Businger (LKB) model ${ }^{15,16}$ in order to enable a good comparison with the $10 \mathrm{~m}$ scatterometer winds.

Table 3 shows that the OSCAT-2 wind component standard deviations for $25 \mathrm{~km}$ are slightly lower than those for $50 \mathrm{~km}$. The higher resolution $25 \mathrm{~km}$ winds contain more small scale features and hence better mimic the local point measurements of the buoys. The wind component standard deviations are lower for OSCAT-2 than for OSCAT-1, probably due to the improvements in the instrument characteristics. Both OSCAT-2 and OSCAT-1 show higher wind component standard deviations than QuikSCAT, which we attribute to the lower instrument noise in the SeaWinds instrument.

Collocated data sets of OSCAT-2 $25 \mathrm{~km}$ and $50 \mathrm{~km}$, ECMWF and buoy winds spanning nine months were used in triple collocation ${ }^{17,18}$. Table 4 lists the error variances of the buoy, OSCAT-2 and ECMWF winds from the scatterometer resolution perspective. When we compare the $50 \mathrm{~km}$ OSCAT-2 product with the $25 \mathrm{~km}$ OSCAT-2 product, we see an increase of the buoy wind error standard deviations and a decrease of the ECMWF wind standard deviations. This is due to the coarser resolution of the $50 \mathrm{~km}$ product, which contains less small scale information and in this respect better resembles the ECMWF winds and worse resembles the local buoy winds. The errors of the $25 \mathrm{~km}$ OSCAT-2 winds are larger than those of the $50 \mathrm{~km}$ winds. This is most probably due to the larger noise in the $25 \mathrm{~km}$ wind retrievals.

For comparison, triple collocation results from reprocessed OSCAT-1 and SeaWinds are shown in Table 4 as well. Note that the reprocessed data sets contain ECMWF reanalysis ERA-interim model winds which are on coarser

Table 3. Seasonally representative buoy comparison results of OSCAT-2 $25 \mathrm{~km}$ and $50 \mathrm{~km}$ wind products from October 2016 to July 2017, compared with reprocessed OSCAT-1 wind products from October 2012 to July 2013 (ref. 22) and reprocessed SeaWinds wind products from October 2008 to July 2009 (ref. 23)

\begin{tabular}{lcccc}
\hline & $\begin{array}{c}\text { No. of wind } \\
\text { vectors }\end{array}$ & Speed bias & Stdev $u$ & Stdev $v$ \\
\hline 25 km OSCAT-2 & 23,148 & 0.13 & 1.83 & 1.76 \\
25 km OSCAT-1 & 36,985 & -0.09 & 1.85 & 1.82 \\
25 km SeaWinds & 39,240 & -0.16 & 1.72 & 1.68 \\
50 km OSCAT-2 & 23,405 & 0.16 & 1.85 & 1.80 \\
50 km OSCAT-1 & 37,126 & -0.03 & 1.84 & 1.83 \\
50 km SeaWinds & 41,558 & -0.14 & 1.73 & 1.70 \\
\hline
\end{tabular}

resolution and from an older ECMWF model version than the operational model winds used in the OSCAT-2 data. This results in somewhat higher (by $\sim 0.2 \mathrm{~m} / \mathrm{s}$ ) model wind error values in the reprocessed wind data sets. It appears that the error values for OSCAT-2 are lower than the corresponding errors for OSCAT-1 in line with Table 1. The OSCAT-2 scatterometer winds are of excellent quality: at $25 \mathrm{~km}$ scale the error in the wind components is less than $0.8 \mathrm{~m} / \mathrm{s}$; at $50 \mathrm{~km}$ scale it is less than $0.6 \mathrm{~m} / \mathrm{s}$ and improved with respect to OSCAT-1.

\section{Performance comparison against models}

$J P L$ processing comparison results: Using the processing methods outlined previously, JPL processed the 1.1.3 SCATSAT-1 L1B data to ocean surface winds using JPL's modular C++ scatterometer processing software. In Figure 10 we plot the wind speed bias, wind speed root mean square (RMS) difference, wind direction RMS, and wind direction bias - all computed with respect to ECMWF. We use the calibration shown in Table 4 for OSCAT-2, and find that this calibration gives us reasonably unbiased wind retrieval performance as compared to ECMWF. We see that the OSCAT-2 data product meets the QuikSCAT science requirements of $<2 \mathrm{~m} / \mathrm{s}$ RMS speed and about $20^{\circ}$ RMS direction difference.

In Figure 11 we plot the wind speed bias and RMS difference as compared to ECMWF, as well as the same for the zonal and meridional components. Finally, we also plot the total counts and percent of rain flagged data in the lower-right. We only show rain-free data in these figures. We do not see any swath-based artifacts in these overall maps, however, we do see some rain contamination getting through. Again, these maps show that we are meeting the QuikSCAT level science requirements of $2 \mathrm{~m} / \mathrm{s}$ RMS speed overall.

KNMI processing comparison results: Figure 8 shows two-dimensional histograms of the retrieved winds versus stress-equivalent $10 \mathrm{~m}$ ECMWF background winds for the $50 \mathrm{~km}$ wind product, after rejection of $\sim 6 \%$ of quality controlled (KNMI QC flagged) wind vectors. The data for these plots are from 29 consecutive orbits from 4 to 5 April 2018. Due to the large daily number of measurements and collocations with the model data, two days are sufficient to obtain reliable and detailed statistics. The top left plot corresponds to wind speed (bins of $0.5 \mathrm{~m} / \mathrm{s}$ ) and the top right plot to wind direction (bins of $2.5^{\circ}$ ). The latter are computed only for ECMWF winds larger than $4 \mathrm{~m} / \mathrm{s}$. The bottom plots show the $u$ and $v$ wind component statistics (bins of $0.5 \mathrm{~m} / \mathrm{s}$ ). The contour lines are in logarithmic scale, thus emphasizing low bin sampling.

We note two remaining general limitations from Figure 8. First, the wind direction bias modulation of about $10^{\circ}$ is partially related to systematic biases in global NWP 
Table 4. Error standard deviations in $u$ and $v$ wind components from triple collocation of OSCAT-2 $25 \mathrm{~km}$ and $50 \mathrm{~km}$ wind products with buoy and ECMWF forecast winds, seen from the scatterometer perspective. The results were obtained for the period of October 2016 to July 2017. The OSCAT-1 results over 2009-2014 (ref. 22) and the SeaWinds results over 1999-2009 (ref. 23) are shown for comparison

\begin{tabular}{|c|c|c|c|c|c|c|}
\hline & \multicolumn{2}{|c|}{ Scatterometer } & \multicolumn{2}{|c|}{ Buoys } & \multicolumn{2}{|c|}{ ECMWF } \\
\hline & $\varepsilon_{u}(\mathrm{~m} / \mathrm{s})$ & $\varepsilon_{v}(\mathrm{~m} / \mathrm{s})$ & $\varepsilon_{u}(\mathrm{~m} / \mathrm{s})$ & $\varepsilon_{v}(\mathrm{~m} / \mathrm{s})$ & $\varepsilon_{u}(\mathrm{~m} / \mathrm{s})$ & $\varepsilon_{v}(\mathrm{~m} / \mathrm{s})$ \\
\hline $25 \mathrm{~km}$ OSCAT-2 & 0.77 & 0.60 & 1.37 & 1.40 & 1.10 & 1.13 \\
\hline 25 km OSCAT-1 & 0.80 & 0.71 & 1.44 & 1.45 & 1.33 & 1.40 \\
\hline $25 \mathrm{~km}$ SeaWinds & 0.64 & 0.54 & 1.39 & 1.41 & 1.28 & 1.35 \\
\hline $50 \mathrm{~km}$ OSCAT-2 & 0.60 & 0.44 & 1.45 & 1.50 & 0.99 & 1.00 \\
\hline $50 \mathrm{~km}$ OSCAT-1 & 0.61 & 0.48 & 1.53 & 1.54 & 1.20 & 1.29 \\
\hline $50 \mathrm{~km}$ SeaWinds & 0.46 & 0.40 & 1.50 & 1.49 & 1.20 & 1.28 \\
\hline
\end{tabular}
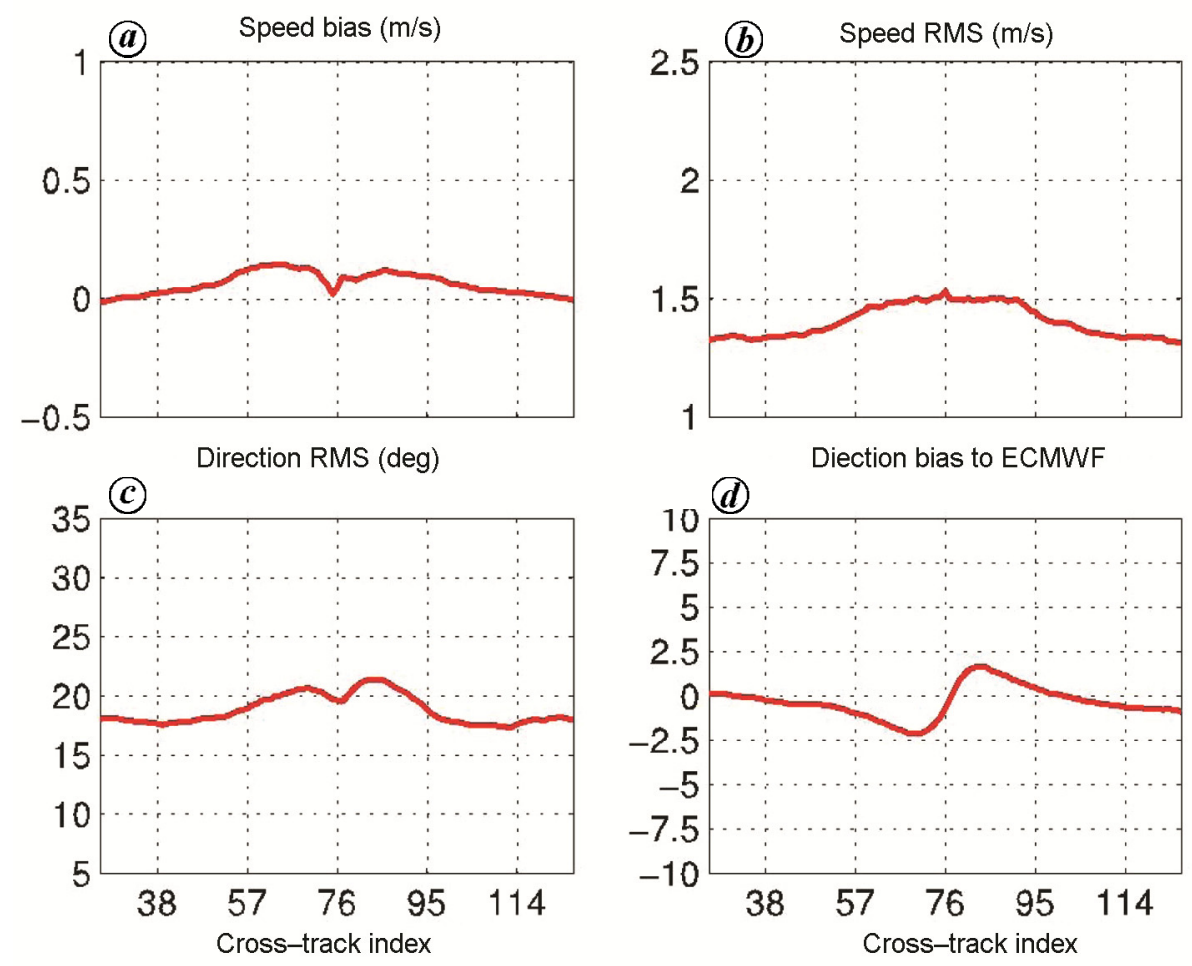

Figure 10. JPL retrievals of SCATSAT-1 version 1.1 .3 with $(\boldsymbol{a})$ speed bias $(\mathrm{m} / \mathrm{s})$ as compared to ECMWF, (b) Speed RMS (m/s) versus ECMWF, (c) direction RMS difference (degrees) to ECMWF, (d) direction bias (degrees) to ECMWF. A cross track index unit on the $x$-axis is $12.5 \mathrm{~km}$ long. Data from 2016/280 through 2017/203 were used for these plots.

models for stable stratification. On top of that, there are shortcomings in the wind direction modulation of the NSCAT-4 Geophysical Model Function, leading to systematic wind direction errors. There are however also wind direction retrieval biases in the nadir swath due to poor beam azimuth separation. This leads to wind directions tending towards the sub-satellite track ${ }^{6}$. Research is ongoing to reduce these general pencil-beam scatterometer retrieval errors.

The second limitation is that positive zonal wind component biases remain for high winds. These issues are addressed in current developments, but do pose a major problem to the value of current SCASAT-1 wind data. A correction of the $H H$ wind direction modulation appears to be the solution ${ }^{6}$ and is being implemented at KNMI.

\section{Impact on operational weather forecasting}

Given the performance and caveats outlined above, the SCASAT-1 data are now being used operationally both in India and Europe, while it is still under evaluation by NOAA in the USA. The paragraphs below present a snapshot of SCATSAT-1 impacts at the time of writing and given the SCATSAT-1 level 1.1.3 L1B data. 

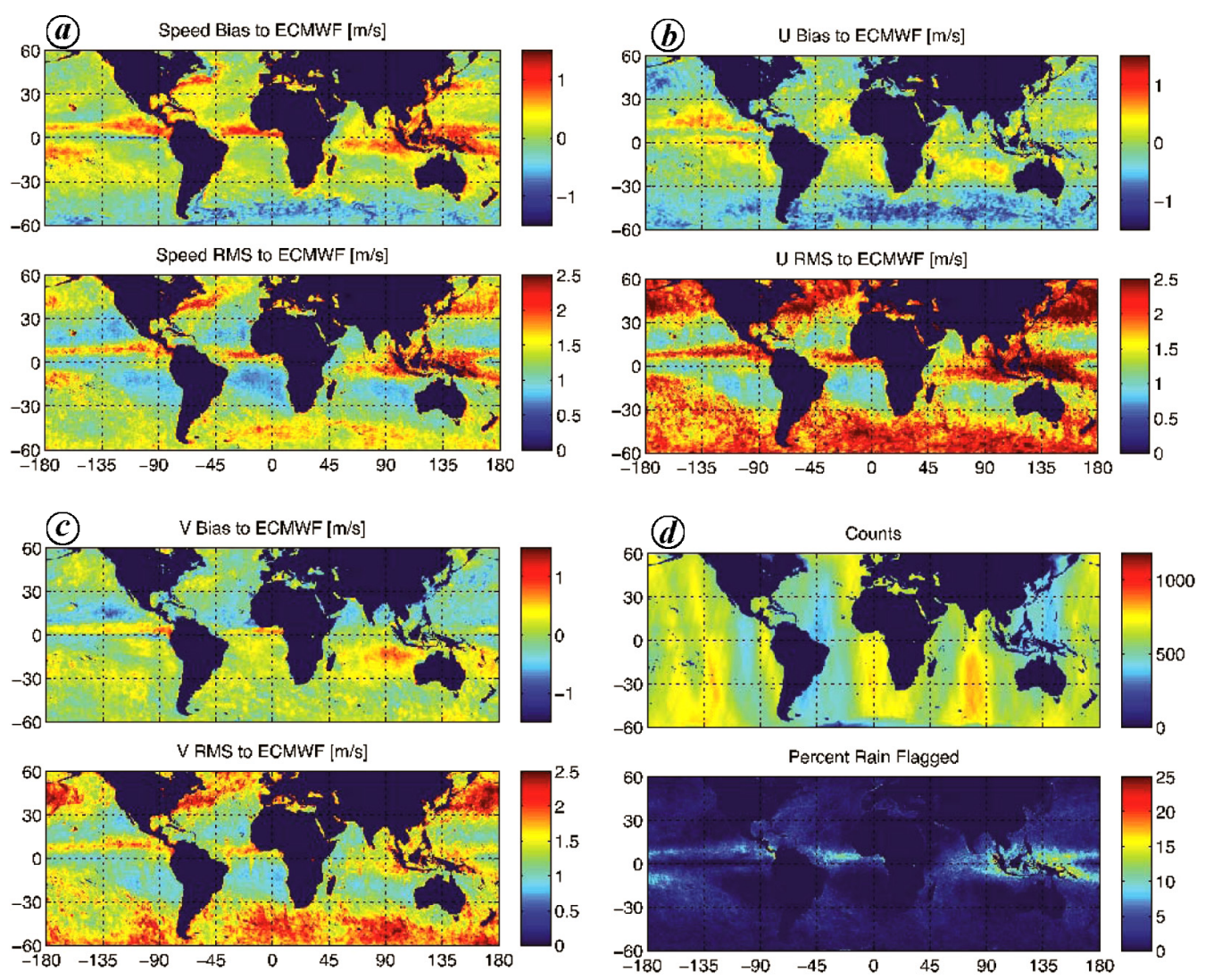

Figure 11. Wind speed (a), zonal-component (b), meridional-component $(\boldsymbol{c})$, and counts percent rain flagged (d). In each is the bias (top) and RMSD (bottom) as compared to ECMWF (except for the counts/percent rain flagged). Data from 2016/280 through 2017/203 were used for these plots.

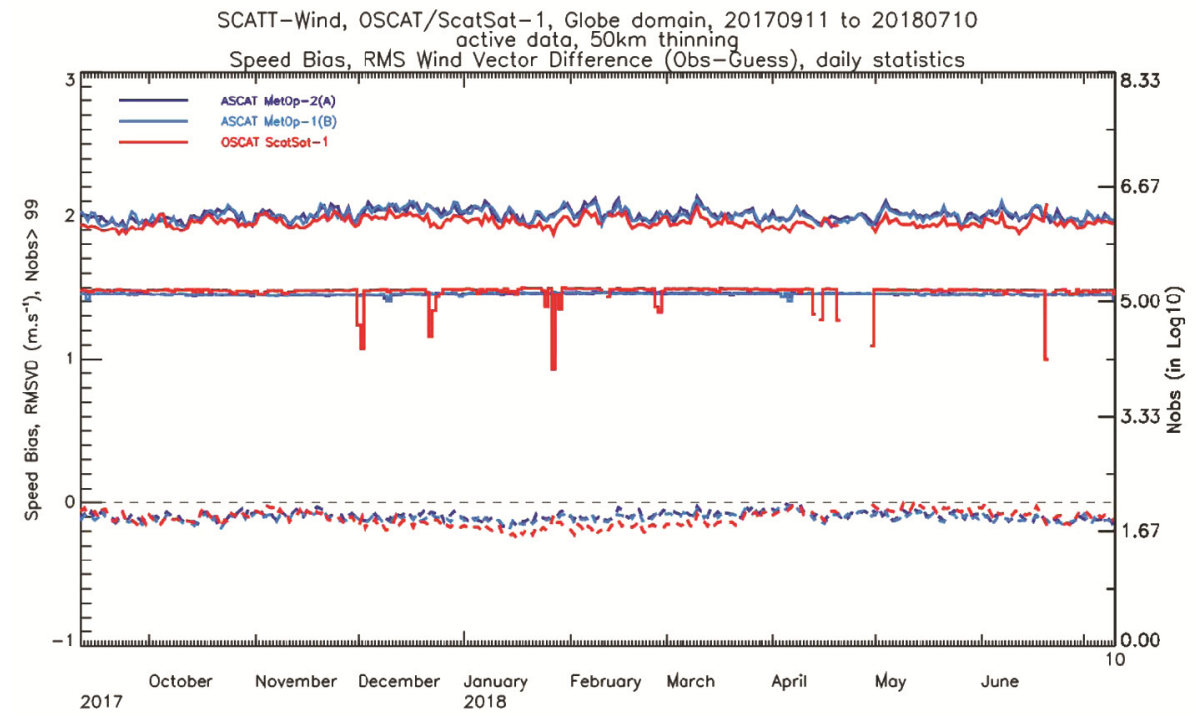

Figure 12. Departures of the OSI SAF OSCAT-2 and ASCAT winds to a version of the Météo-France operational global model ARPEGE. Data usable for the assimilation, after QC and $50 \mathrm{~km}$ thinning.

\section{Impact for Indian operational weather forecasting}

In India, SCATSAT-1 data has been used operationally by the Indian Meteorological Department (IMD) and National Centre for Medium Range Weather Forecasting
(NCMRWF). In both organizations, the SCATSAT-1 data have been utilized as an initial condition and also for assimilation in the operational NWP models. IMD and NCMRWF have both reported (private communication) that SCATSAT-1 wind data products have impacted CURRENT SCIENCE, VOL. 117, NO. 6, 25 SEPTEMBER 2019 
positively their operational model forecasts. Apart from the IMD and NCMRWF, ISRO's Space Applications Centre (SAC) also applied the SCATSAT-1 data in prediction of cyclogenesis in Indian Ocean, along with intensity and track prediction for cyclones, and have shown positive impact in cyclone forecasting skill.

\section{Impact for weather forecasting in Europe}

Just as for OSCAT-1 (ref. 19), the OSI SAF distributes the OSCAT-2 winds to main European users for testing in NWP. Figure 12 shows the stability of this wind product and thus of the OSCAT-2 instrument and processing since September 2017. Météo-France moreover reports a low wind speed bias at $0^{\circ} \mathrm{C}$ and a high bias at $30^{\circ} \mathrm{C}$, both about $0.8 \mathrm{~ms}^{-1}$ in size. KNMI is implementing a SSTdependent $\mathrm{GMF}^{20}$ for the OSCAT-2 operational processing in the OSI SAF. Mean biases have a particularly detrimental effect in NWP and bias correction schemes are common place.

The UK Met Office tested the OSI SAF winds after applying a speed-dependent bias correction against their model winds. The forecast scorecard versus ECMWF analyses in Figure 13 shows small, statistically significant, positive impacts at short lead times for, e.g. PMSL in the extra-tropics, and $10 \mathrm{~m}$ winds in the tropics and southern hemisphere. In these experiments also ASCAT and WindSat ocean vector winds are used and adding ScatSat winds improves the standard deviation of the difference $(\mathrm{O}-\mathrm{B})$ between short-range forecasts and these independent observations. Moreover, assimilation of SCATSAT-1 data also improves the O-B fit to other observations, e.g. CrIS temperature sounding channels improved by $0.5 \%$ in the lower troposphere. Given the overlap in sampling of the ASCATs and OSCAT-2, this is very encouraging indeed.

\section{Discussion and prospects}

All members of the CalVal team concur that OSCAT-2 winds have overall better quality than OSCAT-1 winds and meet the pre-launch performance goals set by ISRO for the SCATSAT-1 mission. Furthermore, the OSCAT-2 sensor seems stable, within the bounds of the validation possible in the relatively short mission duration. This means that OSCAT-2 on SCATSAT-1 is a good candidate for continuing the Ku-band climate data record started by SeaWinds on QuikSCAT and OSCAT-1 on Oceansat-2. The present data quality is already good enough to show positive impacts on weather forecasting for some agencies. NOAA, however, still is evaluating how to compensate for some of the features described below before making the data fully operational.

Although the precision of the instrument seems acceptable, systematic calibration offsets have been reported by both KNMI and JPL by comparing against QuikSCAT data and NWP outputs. Simple calibration offsets can be applied to the data after L1B processing, but doing so has proved insufficient to get a completely consistent data set. For instance, JPL reports that the calibration values obtained from land and ocean calibration are different, whereas they appeared consistent for the absolute calibration of OSCAT-1. A potential cause for this inconsistency has been identified by KNMI as being potentially due to a system non-linearity, which they correct with a simple empirical correction above $-19 \mathrm{~dB}$, causing backscatter measurements to appear low relative to earlier

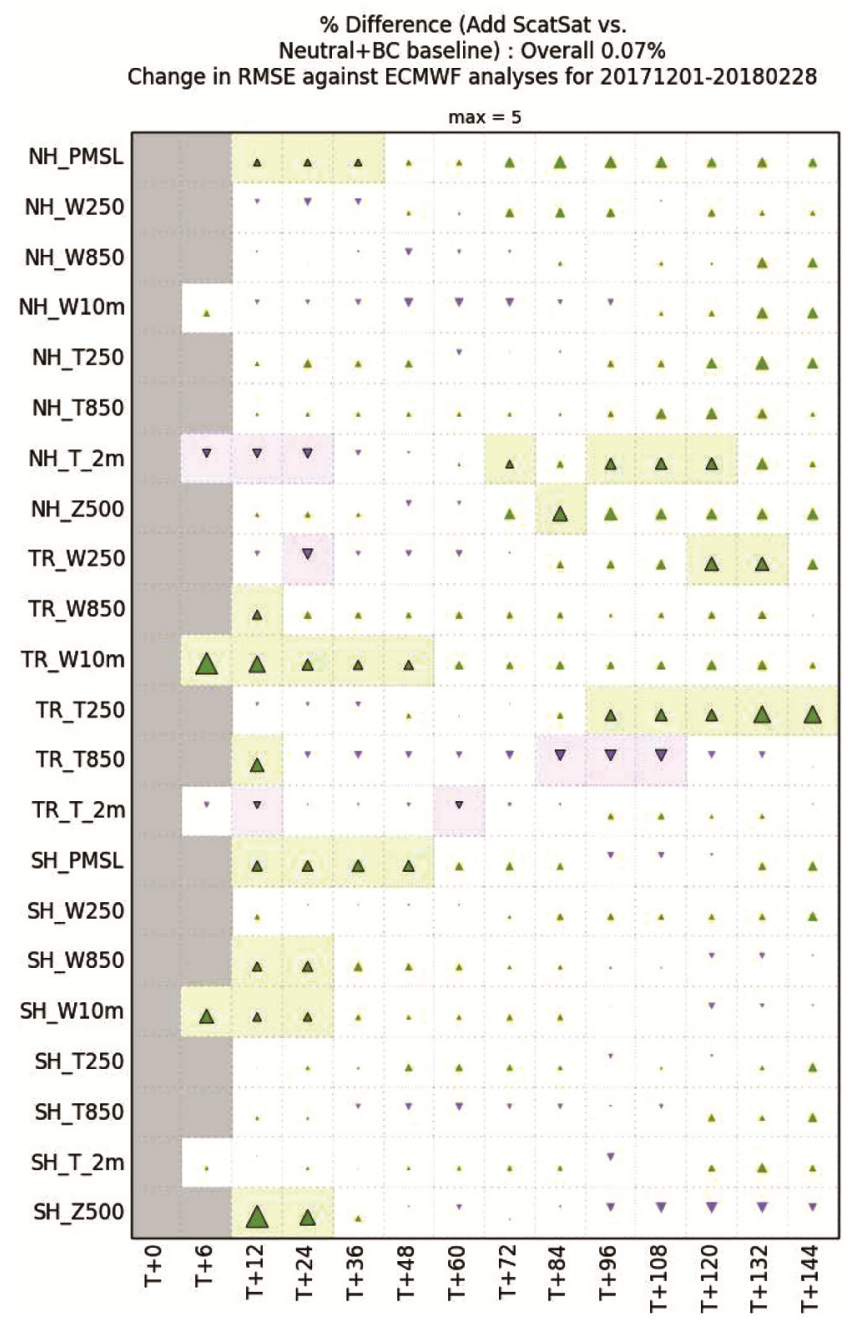

Figure 13. Impact of the OSI SAF OSCAT-2 winds at the UK Met Office. The forecasts are compared to the operational ECMWF analyses, without ScatSat-1 winds. Green (purple) triangles indicate better (worse) RMS error comparison of the ScatSat-1 forecasts with ECMWF analyses (RMS1) as compared to the reference experiment without ScatSat-1 (RMS2). The larger the triangle, the larger the absolute difference |RMS1-RMS2|. Impacts that are statistically significant at the $95 \%$ level are denoted by a shaded box. Northern, Southern Hemisphere and Tropics (latitude $<20^{\circ}$ ) are denoted resp. by $\mathrm{NH}, \mathrm{SH}$ and TR. Forecast parameters are mean sea level pressure (PMSL), wind (W) and temperature (T) at $250 / 850 \mathrm{hPa}, \mathrm{W}$ at $10 \mathrm{~m}, \mathrm{~T}$ at $2 \mathrm{~m}$ and geopotential height at $500 \mathrm{hPa}(\mathrm{Z} 500)$. 
scatterometers. The root origin of this non-linearity is still unknown. Adoption of the SCATSAT-1 data into the climate data record will likely require understanding and resolution of these systematic effects.

Moreover, due to its particular orbit characteristics, OSCAT-2 provides abundant collocations with the ASCAT scatterometers, which is useful for improvements in intercalibration and wind processing of all these systems. Detailed analysis of the GMF and wind retrieval properties is ongoing in the EUMETSAT OSI SAF ${ }^{6}$ and shared with ISRO, most likely leading to further improvement and reduction of the remaining minor wind direction and wind component anomalies reported here.

- Since precise absolute calibration is lacking, intercalibration is needed to obtain consistent backscatter from multiple scatterometers.

- In line with the quality of the retrieved winds, NWP impact is demonstrated, even though OSCAT-2 overlap with ASCAT-A and -B is large and thus redundancy of data exists at 9:00 local time in the morning and evening.

- OSCAT-3 on OceanSat-3 is expected to provide substantial impact in NWP, just like its predecessor OSCAT-1, due to a better local observation time.

1. Fore, A. G., Neumann, G., Freedman, A. P., Chaubell, M. J., Tang, W., Hayashi, A. K. and Yueh, S. H., Aquarius scatterometer calibration. IEEE J.-STARS, 2015, 8(12), 5424-5432.

2. Shimada, M., Isoguchi, O. and Isono, K., PALSAR radiometric and geometric calibration. IEEE Trans. Geosci. Remote Sens., 2009, 47(12), 3915-3932.

3. Shimada, M., Long-term stability of L-band normalized radar cross section of Amazon rainforest using the JERS-1 SAR. Can. J. Remote Sens., 2005, 31(1), 132-137.

4. Madsen, N. M. and Long, D. G., Calibration and validation of the RapidScat scatterometer using tropical rainforests. IEEE Trans. Geosci. Remote Sens., 2016, 54(5), 2846-2854.

5. Jaruwatanadilok, S., Stiles, B. W. and Fore, A. G., Crosscalibration between QuikSCAT and Oceansat-2. IEEE Trans. Geosci. Remote Sens., 2014, 52(10), 6197-6204.

6. Wang, Z., Stoffelen, A., He, Y., Zhang, B., Verhoef, A., Lin, W., $\mathrm{Li}, \mathrm{X}$. and Shao, F., An improved wind direction modulation for Ku-band geophysical model functions, based on ASCAT and OSCAT-2 collocations. J. Geophys. Res. Oceans, manuscript 2018JC014389 (under review).

7. Snyder, J. P., Map projections used by the US Geological Survey, Technical Report Bulletin 1532, USGS 1982.

8. Fore, A. G., Stiles, B. W., Chau, A. H., Williams, B. A., Dunbar, R. S. and Rodriguez, E., Point-wise wind retrieval and ambiguity removal improvements for the QuikSCAT climatological data set. IEEE Trans. Geosci. Remote Sens., 2014, 53(1).
9. Ricciardulli, L. and Wentz, F., A scatterometer geophysical model function for climate-quality winds: QuikSCAT Ku-2011. J. Atmos. Oceanic Technol., 2015, 32, 1829-1846.

10. Stiles, B. W., Pollard, B. D. and Dunbar, R. S., Direction interval retrieval with thresholded nudging: a method for improving the accuracy of QuikSCAT winds. IEEE Trans. Geosci. Remote Sensing, 2002, 40(1), 79-89.

11. EUMETSAT OSI SAF, Product Requirements Document, SAF/OSI/CDOP3/MF/MGT/PL/2-001, 2017.

12. EUMETSAT OSI SAF, Service Specification Document, SAF/OSI/CDOP3/MF/MGT/PL/003, 2017.

13. EUMETSAT OSI SAF, ScatSat-1 wind Product User Manual, SAF/OSI/CDOP2/KNMI/TEC/MA/287, 2018.

14. SCATSAT-1 Data Products and Retrieval Team, Algorithm and Theoretical Basis Document for SCATSAT1 Data Products, ISRO/SAC/SCATSAT1/DP/ATBD/V1.0, Dec 2016.

15. Bidlot, J., Holmes, D., Wittmann, P., Lalbeharry, R. and Chen, H., Intercomparison of the performance of operational ocean wave forecasting systems with buoy data. Weather Forecast., 2002, 17, 287-310.

16. Liu, W. T., Katsaros, K. B. and Businger, J. A., Bulk parameterization of air-sea exchanges of heat and water vapor including the molecular constraints in the interface. J. Atmos. Sci., 1979, 36.

17. Stoffelen, A., Toward the true near-surface wind speed: error modeling and calibration using triple collocation. J. Geophys. Res., 1998, 103(C4), 7755-7766; doi:10.1029/97JC03180.

18. Vogelzang, J., Stoffelen, A., Verhoef, A. and Figa-Saldana, J., On the quality of high-resolution scatterometer winds. J. Geophys. Res., 2011, 116, C10033; doi:10.1029/2010JC006640.

19. Stoffelen, A. et al., Research and Development in Europe on Global Application of the OceanSat-2 Scatterometer Winds, KNMI, Report numbers: NWPSAF-KN-TR-022 and SAF/ OSI/CDOP2/KNMI/TEC/RP/1962013, 2013; https://www.nwpsaf. eu/publications/tech_reports/nwpsaf-kn-tr-022.pdf.

20. Wang, Z. et al., An SST-dependent Ku-band geophysical model function for RapidScat. J. Geophys. Res. Oceans, 2017, 122, 3461-3480; doi:10.1002/2016JC012619.

21. EUMETSAT OSI SAF, ScatSat-1 wind validation report, SAF/OSI/CDOP3/KNMI/TEC/RP/324, v1.0, 2018.

22. Verhoef, A., Vogelzang, J. and Stoffelen, A., Oceansat-2 L2 winds Data Record validation report, SAF/OSI/CDOP3/KNMI/TEC/ $\mathrm{RP} / 298$.

23. Verhoef, A., Vogelzang, J. and Stoffelen, A., Reprocessed SeaWinds L2 winds validation report, SAF/OSI/CDOP2/KNMI/ $\mathrm{TEC} / \mathrm{RP} / 221$.

ACKNOWLEDGEMENTS. J.P.L. and K.N.M.I. are grateful to ISRO for the SCATSAT-1 data and for the responsiveness over the CalVal period. KNMI moreover acknowledges EUMETSAT and its OSI SAF for providing the resources to advance the SCATSAT-1 services for its users. We are also grateful to NOAA's participation and contributions to the CalVal effort, which are reflected in the results reported here. Portions of the research presented in the paper were carried out at the Jet Propulsion Laboratory, California Institute of Technology, under contract with the National Aeronautics and Space Administration. US Government sponsorship acknowledged.

doi: $10.18520 / \mathrm{cs} / \mathrm{v} 117 / \mathrm{i} 6 / 959-972$ 